\title{
Expression of ACE2, the SARS-CoV-2 Receptor, in Lung Tissue of Patients With Type 2 Diabetes
}

\author{
Sara R.A. Wijnant, ${ }^{1,2,3,4}$ Merel Jacobs, ${ }^{1}$ Hannelore P. Van Eeckhoutte, ${ }^{1}$ Bruno Lapauw, ${ }^{5}$ Guy F. Joos, ${ }^{1}$ \\ Ken R. Bracke, ${ }^{1}$ and Guy G. Brusselle ${ }^{1,2,4}$ \\ Diabetes 2020;69:2691-2699 | https://doi.org/10.2337/db20-0669
}

Increased expression of pulmonary ACE2, the SARSCoV-2 receptor, could contribute to increased infectivity of COVID-19 in patients with diabetes, but ACE2 expression has not been studied in lung tissue of subjects with diabetes. We therefore studied ACE2 mRNA and protein expression in lung tissue samples of subjects with and without diabetes that were collected between 2002 and 2020 from patients undergoing lobectomy for lung tumors. For RT-PCR analyses, samples from 15 subjects with diabetes were compared with 91 randomly chosen control samples. For immunohistochemical staining, samples from 26 subjects with diabetes were compared with 66 randomly chosen control samples. mRNA expression of ACE2 was measured by quantitative RT-PCR. Protein levels of ACE2 were visualized by immunohistochemistry on paraffin-embedded lung tissue samples and quantified in alveolar and bronchial epithelium. Pulmonary ACE2 mRNA expression was not different between subjects with or without diabetes. In contrast, protein levels of ACE2 were significantly increased in both alveolar tissue and bronchial epithelium of patients with diabetes compared with control subjects, independent of smoking, chronic obstructive pulmonary disease, BMI, renin-angiotensin-aldosterone system inhibitor use, and other potential confounders. To conclude, we show increased bronchial and alveolar ACE2 protein expression in patients with diabetes. Further research is needed to elucidate whether upregulation of ACE2 expression in airways and lungs has consequences on infectivity and clinical outcomes of COVID-19.
Severe acute respiratory syndrome coronavirus 2 (SARS$\mathrm{CoV}-2$ ) is responsible for a novel pandemic that emerged in China and spread globally. Coronavirus disease 19 (COVID-19) is the third large-scale pandemic caused by coronaviruses after SARS-1 in 2002 and Middle East respiratory syndrome in 2012 (1). The clinical course of the disease ranges from an asymptomatic course to acute respiratory disease, pneumonia, and even death (1). Importantly, although SARS-CoV-2 can infect any individual, an increased risk for hospitalization and death as a result of COVID-19 is reported in older subjects, smokers, and patients with comorbidities such as hypertension, chronic obstructive pulmonary disease (COPD), obesity, and especially diabetes (2-10). Patients with diabetes are known to be at increased risk for both mortality and the development of complications as a result of infection-related diseases (11). More specifically, in the case of COVID-19, early analysis on a small cohort in China showed that diabetes accounted for $20 \%$ of intensive care unit admissions (12). In Italy, $20 \%$ up to two-thirds of people who died as a result of COVID-19 had diabetes $(13,14)$. A recent meta-analysis confirmed that diabetes can worsen the outcome of a SARS-CoV-2 infection (15). Furthermore, it has been suggested that poor glycemic control makes the disease more severe and that both patients with type 2 diabetes and patient with the metabolic syndrome might have an up to 10 times greater risk of death as a result of COVID-19 (16-18).

\footnotetext{
'Laboratory for Translational Research in Obstructive Pulmonary Diseases, Department of Respiratory Medicine, Ghent University Hospital, Ghent, Belgium 2Department of Epidemiology, Erasmus Medical Center, Rotterdam, the Netherlands

3Department of Bioanalysis, Faculty of Pharmaceutical Sciences, Ghent University, Ghent, Belgium

${ }^{4}$ Department of Respiratory Diseases, Erasmus Medical Center, Rotterdam, the Netherlands

${ }^{5}$ Department of Endocrinology, Ghent University Hospital, Ghent, Belgium

Corresponding author: Sara R.A. Wijnant, sara.wijnant@ugent.be

Received 26 June 2020 and accepted 30 September 2020
}

This article contains supplementary material online at https://doi.org/10.2337/ figshare.13027727.

This article is part of a special article collection available at https://diabetes .diabetesjournals.org/collection/diabetes-and-COVID19-articles.

S.R.A.W. and M.J. contributed equally.

K.R.B. and G.G.B. supervised the work equally.

(C) 2020 by the American Diabetes Association. Readers may use this article as long as the work is properly cited, the use is educational and not for profit, and the work is not altered. More information is available at https://www.diabetesjournals .org/content/license. 
Since diabetes affects $>460$ million people worldwide (19), it is crucial to elucidate the pathophysiological mechanisms underlying the association between diabetes and SARS-CoV-2 severity. SARS-CoV-2 binds to ACE2 as the host cellular entry receptor $(1,20)$, the expression of which has been reported to be higher in smokers and patients with COPD $(21,22)$. It has been suggested that patients with diabetes exhibit increased infectivity for SARS-CoV-2 because of higher pulmonary ACE2 mRNA levels (23). Although supported by findings in nonobese diabetic mice (24), studies on human lung tissue and ACE2 protein level are scarce.

We hypothesized that patients with type 2 diabetes show increased expression of ACE2, the SARS-CoV-2 entry receptor, in the lung. Therefore, we aimed to determine pulmonary ACE2 mRNA expression and ACE2 protein levels in both alveolar tissue and bronchial epithelium of patients with and without diabetes. Moreover, we aimed to elucidate the independent clinical determinants of lungspecific ACE2 expression by linear regression analyses.

\section{RESEARCH DESIGN AND METHODS}

Data are reported according to the Strengthening the Reporting of Observational Studies in Epidemiology checklist for cross-sectional studies $(25,26)$.

\section{Human Lung Tissue Biobank}

This cross-sectional observational study included lung samples from our large tissue biobank at Ghent University Hospital, currently encompassing 360 subjects. A pathologist collected lung tissue derived from patients diagnosed with solitary pulmonary tumors at maximum distance from the pulmonary lesions and without signs of retroobstructive pneumonia or tumor invasion. None of the surgical patients were treated with neoadjuvant chemotherapy. All samples were collected between 2002 and 2020 in a nonprobabilistic manner before the first reported case of COVID-19 in Belgium (21 February 2020). Patients provided written informed consent. This study was approved by the medical ethical committee of Ghent University Hospital (2011/0114; 2016/0132; 2019/0537).

\section{Selection of Lung Tissue Samples for This Study}

A flowchart illustrating the enrollment of subjects for immunohistochemical (IHC) $(n=92)$ and quantitative RT-PCR $(n=106)$ analyses is shown in Supplementary Fig. 1. Since we initially aimed at examining ACE2 expression in patients with and without COPD through IHC and RT-PCR analyses, and preliminary results seemed suspicious of high ACE2 protein levels in patients with diabetes comorbidity, we extended the initial 10 included patients with diabetes for IHC with 16 more in order to investigate the association between diabetes and ACE2 profoundly. In total, we acquired lung tissue of 26 patients with diabetes and a random sample of 66 control subjects for the IHC analysis. The initial RT-PCR analyses were available in a larger study sample that included 15 patients with diabetes, which were all included for this study, as well as results from 91 control subjects. Three patients with diabetes were not included in the IHC analyses because, owing to the retrospective nature of acquiring clinical information on diabetes, the diagnosis of diabetes was assigned after initializing IHC analyses.

\section{Diagnosis of Diabetes}

Diagnosis of diabetes was based on medical history and antidiabetic medication use at the time of surgery, which we obtained at the time of designing this study through reviewing the patients' medical records. The investigator who searched the medical records (S.R.A.W.) was blinded to ACE2 expression, and the investigator who quantified ACE2 expression (M.J.) was blinded to the diagnosis of diabetes.

\section{RNA Extraction and Real-Time PCR Analysis}

RNA extraction and RT-PCR analysis of lung tissue were performed as described previously (27). Briefly, RNA extraction from lung tissue blocks was performed with the miRNeasy Mini Kit (QIAGEN), according to the manufacturer's instructions. Next, cDNA was prepared with the EvoScript Universal cDNA Master Kit (Roche). Gene expression of ACE2 and the reference genes were measured using Taqman Gene Expression Assays (Applied Biosystems, Foster City, CA). The reference genes used were GAPDH, peptidylprolyl isomerase A (PPIA), and succinate dehydrogenase complex flavoprotein subunit A (SDHA). Data were analyzed using the standard curve method, and expression of ACE2 was calculated relative to the expression of three reference genes using the geNorm applet according to the guidelines and theoretical framework previously described (28).

\section{ACE2 IHC}

ACE2 protein levels were determined using sections from formalin-fixed paraffin-embedded lung tissue blocks. Antigen retrieval was performed with citrate buffer (ScyTek Laboratories) before incubation with anti-ACE2 antibody (polyclonal rabbit anti-human, ab15348; Abcam). Next, slides were colored with diaminobenzidine (Dako, Carpinteria, CA) and counterstained with Mayer hematoxylin (SigmaAldrich, St. Louis, MO). The isotype control was rabbit IgG (AB-150-C; R\&D Systems).

\section{Quantification of ACE2 in Alveolar Tissue and Airway Epithelium}

To determine ACE2 protein levels in alveolar tissue, 10 images of alveolar tissue (not containing airways, arterioles, or venules) were recorded from an average of three lung tissue blocks per patient. The intensity of brown ACE2+ staining was selected by specific hue, lightness, and saturation values using AxioVision software (Zeiss, Oberkochen, Germany). To restrict our scoring to a specific signal, the same hue, saturation, and lightness values were applied for all samples. The ACE2+ signal was calculated 
only within the alveolar tissue and normalized to the total area of alveolar tissue present in each image. The final score of each patient was the median score of 10 images. Additionally, the number of ACE2+ cells was manually counted in each image and again normalized to the total area of alveolar tissue.

To quantify the amount of ACE2 protein levels in airway epithelium, images of airways were recorded from an average of three tissue blocks per patient. The number of airways per patient was between 3 and 20. The amount of ACE2+ signal was measured within the airway epithelial layer and normalized to per unit length of basement membrane $(\mathrm{Pbm})$. The final score of each patient was the average ACE2 staining in all airways present in all tissue blocks available for that patient.

\section{Covariates}

Clinical patient characteristics were obtained through questionnaire data and medical records. Lung function, smoking status, and BMI were obtained at the time of tissue sampling. Ex-smoking was defined as smoking cessation $>1$ year. COPD was defined by spirometry as postbronchodilator forced expiratory volume in $1 \mathrm{~s} /$ forced vital capacity ratio $<70 \%$. Other clinical characteristics included hypertension (hypertension in medical history, use of antihypertensive medication, systolic blood pressure $\geq 140 \mathrm{mmHg}$, or diastolic blood pressure $\geq 90 \mathrm{mmHg}$ ), atherosclerotic vascular disease (history of coronary, carotid, or peripheral artery stenosis; myocardial infarction; or stroke), antihypertensive medication use ( $\beta$-blockers, diuretics, calcium-channel blockers, and renin-angiotensinaldosterone-system [RAAS] inhibitors encompassing ACE inhibitors and angiotensin receptor blockers [ARBs]), and use of other drugs of interest (including inhaled corticosteroids, oral corticosteroids, metformin, insulin, sulfonylureas, glinides, glitazones, dipeptidyl peptidase 4 inhibitors, and statins).

White blood cell count, C-reactive protein, blood glucose levels, and serum creatinine levels were collected from the most recent blood sample before surgery. Estimated glomerular filtration rate was calculated on the basis of the Chronic Kidney Disease Epidemiology Collaboration equation (29). $\mathrm{HbA}_{1 c}$ levels were collected from blood samples within a range of 12 months before or after surgery.

\section{Statistical Analysis}

Statistical analysis was performed with R 3.5.1 software, using Student $t$ test for comparing parametrical continuous variables, Mann-Whitney $U$ test for comparing nonparametrical continuous variables, and Fisher exact test for comparing categorical variables. Regression coefficients were calculated using multivariable linear regression analyses. Covariates were selected on the basis of clinical relevance. Nonlinearity of continuous variables was tested using cubic spline polynomials. A Pearson correlation coefficient was calculated for linear associations in scatter plots. $P<0.05$ was considered to be statistically significant.

\section{Data and Resource Availability}

The data sets generated and/or analyzed during the current study are not publicly available but can be made available by the corresponding author upon request.

\section{RESULTS}

\section{Study Population of Subjects With Lung Tissue}

Characteristics of the 92 subjects enrolled in the ACE2 protein quantification by IHC are presented in Table 1 . All 26 subjects with diabetes had type 2 diabetes, and only 3 subjects were insulin dependent. Characteristics of the 106 subjects with ACE2 mRNA expression by quantitative RT-PCR are presented in Supplementary Table 1.

\section{Pulmonary ACE2 Expression in Subjects With and Without Diabetes}

\section{ACE2 Protein Expression in Alveolar Tissue}

IHC revealed a positive signal in alveolar epithelium (Supplementary Fig. $2 A$ and $B$ ). Representative images of ACE2 protein expression in alveolar epithelium of patients with and without diabetes are shown in Fig. $1 A$ and $B$. Both the ACE2 + cell count and percentage of ACE2 + alveolar tissue were significantly increased in subjects with diabetes compared with those without (Fig. $2 A$ and $B$ ), and the latter association was significant independent of smoking status (ACE2+ alveolar tissue percentage in never smokers: median $1.14 \%$ [25th-75th percentile $0.80-1.30 \%$ ] vs. 1.24\% [1.10-1.90\%], $P=0.232$; ex-smokers: $1.16 \%$ [1.01$1.41 \%$ ] vs. $1.96 \%$ [1.46-2.84\%], $P=0.004$; current smokers: $1.62 \%$ [1.00-2.07\%] vs. $2.40 \%$ [1.72-2.81\%], $P=$ 0.016) (Supplementary Fig. 3). In linear regression analysis, the association between diabetes and alveolar ACE2 protein expression remained statistically significant for both the ACE2+ cell count and percentage of ACE2+ alveolar tissue, even after adjusting for age, sex, BMI, smoking status, inhaled and oral corticosteroid use, and comorbidities (Supplementary Fig. $4 A$ and B, model 2).

Interestingly, similar to diabetes, preoperative blood glucose levels $(n=90)$ were positively associated with alveolar tissue ACE2 protein expression, even after adjusting for potential confounders (Supplementary Fig. $4 A$ and $B)$. In the subset of patients with diabetes and available $\mathrm{HbA}_{1 c}$ levels $(n=17)$, those with $\mathrm{HbA}_{1 c}$ levels $\geq 8 \%$ $(64 \mathrm{mmol} / \mathrm{mol})$ had increased levels of alveolar ACE2 protein expression compared with those with $\mathrm{HbA}_{1 \mathrm{c}}$ levels $<8 \%$ (Supplementary Fig. $5 D$ and $E$ ).

\section{ACE2 Protein Expression in Bronchial Epithelium}

IHC revealed a positive signal in bronchial epithelium (Supplementary Fig. $2 C$ and $D$ ). Representative images of ACE2 protein expression in bronchial epithelium of patients with and without diabetes are shown in Fig. $1 C$ and $D$. The level of ACE2 + bronchial epithelium was significantly increased in subjects with diabetes compared 


\begin{tabular}{|c|c|c|c|}
\hline & No type 2 diabetes & Type 2 diabetes & $P$ value \\
\hline Lobectomy patients, $n$ & 66 & 26 & \\
\hline Age (years), mean (SD) & $62.88(9.36)$ & $66.69(6.74)$ & 0.062 \\
\hline Male sex, $n(\%)$ & $37(56.1)$ & $23(88.5)$ & 0.007 \\
\hline BMI $\left(\mathrm{kg} / \mathrm{m}^{2}\right)$, mean (SD) & $25.26(4.87)$ & $30.88(6.24)$ & $<0.001$ \\
\hline $\begin{array}{l}\text { Smoking } \\
\quad \text { Current, } n(\%) \\
\text { Pack-years, median (25th-75th percentile) }\end{array}$ & $\begin{array}{c}31(47.0) \\
30.00(0.00-42.00)\end{array}$ & $\begin{array}{c}9(36.0) \\
40.00(20.00-59.00)\end{array}$ & $\begin{array}{l}0.030 \\
0.034\end{array}$ \\
\hline $\begin{array}{l}\text { Laboratory, mean }(\mathrm{SD}) \\
\text { Glucose }(\mathrm{mg} / \mathrm{L}) \\
\text { Serum creatinine }(\mathrm{mg} / \mathrm{dL}) \\
\text { eGFR }\left(\mathrm{mL} / \mathrm{min} / 1.73 \mathrm{~m}^{2}\right) \\
\text { White blood cell count }\left(\times 10^{9} / \mathrm{L}\right) \\
\text { CRP }(\mathrm{mg} / \mathrm{dL}) \text {, median }(25 \mathrm{th}-75 \text { th percentile) }\end{array}$ & $\begin{array}{c}1.24(0.32) \\
0.86(0.23) \\
75.64(20.89) \\
9.34(3.32) \\
0.70(0.30-2.90)\end{array}$ & $\begin{array}{c}1.61(0.53) \\
0.96(0.19) \\
64.17(14.70) \\
9.98(3.70) \\
2.00(0.68-3.55)\end{array}$ & $\begin{array}{l}<0.001 \\
0.049 \\
0.013 \\
0.432 \\
0.095\end{array}$ \\
\hline $\begin{array}{l}\text { Comorbidities, } n(\%) \\
\text { Hypertension } \\
\text { COPD } \\
\text { Kidney disease } \\
\text { Atherosclerotic vascular disease }\end{array}$ & $\begin{aligned} 37 & (56.1) \\
24 & (36.4) \\
4 & (6.5) \\
11 & (17.5)\end{aligned}$ & $\begin{aligned} 25 & (96.2) \\
13 & (52.0) \\
2 & (7.7) \\
12 & (46.2)\end{aligned}$ & $\begin{array}{l}0.001 \\
0.264 \\
1.000 \\
0.011\end{array}$ \\
\hline $\begin{array}{l}\text { Medication, } n(\%) \\
\text { Metformin* } \\
\text { Insulin* }^{\star} \\
\text { Sulfonylureas* }^{\star} \\
\text { Glinides }^{\star} \\
\text { Glitazones } \\
\text { Diuretics } \\
\text { ACE inhibitors } \\
\text { ARBs } \\
\text { Statins } \\
\text { Inhaled corticosteroids } \\
\text { Oral corticosteroids }\end{array}$ & $\begin{array}{c}0(0.0) \\
0(0.0) \\
0(0.0) \\
0(0.0) \\
0(0.0) \\
9(13.6) \\
5(7.6) \\
11(16.7) \\
14(21.2) \\
14(21.2) \\
7(10.6)\end{array}$ & $\begin{array}{c}19(73.1) \\
3(11.5) \\
6(24.0) \\
3(12.0) \\
1(4.0) \\
8(30.8) \\
10(38.5) \\
3(11.5) \\
14(53.8) \\
8(30.8) \\
3(11.5)\end{array}$ & $\begin{array}{c}<0.001 \\
0.033 \\
<0.001 \\
0.029 \\
0.618 \\
0.108 \\
0.001 \\
0.769 \\
0.005 \\
0.486 \\
1.000\end{array}$ \\
\hline $\begin{array}{l}\text { ACE2 expression } \\
\text { ACE2 }+ \text { alveolar cell count, } n / \mathrm{mm}^{2} \text { (25th-75th percentile) } \\
\text { Percentage ACE2 }+ \text { alveolar tissue (25th-75th percentile) } \\
\text { ACE2 }+ \text { bronchial epithelium, } \mu \mathrm{m} / \mathrm{Pbm} \text { (25th-75th percentile) }\end{array}$ & $\begin{array}{c}558.27(349.19-831.18) \\
1.12(0.94-1.67) \\
6.69(1.88-12.44)\end{array}$ & $\begin{array}{c}805.77(534.88-1,295.32) \\
1.99(1.46-2.74) \\
22.89(9.90-29.97)\end{array}$ & $\begin{array}{l}0.017 \\
<0.001 \\
<0.001\end{array}$ \\
\hline
\end{tabular}

CRP, C-reactive protein; eGFR, estimated glomerular filtration rate. *All antidiabetic medication use is listed in the table, and none of the subjects used glucagon-like peptide 1 analogs, dipeptidyl peptidase 4 inhibitors, or sodium-glucose cotransporter 2 inhibitors.

with control subjects without diabetes (Fig. 2C), independent of smoking status (never smokers: median 3.75 [25th-75th percentile $2.92-7.71]$ vs. 16.32 [11.7622.72] $\mu \mathrm{m}^{2} / \mu \mathrm{m}, P=0.053$; ex-smokers: $7.33[3.57-$ $12.91]$ vs. $17.48[3.97-29.37] \mu \mathrm{m}^{2} / \mu \mathrm{m}, P=0.154$; current smokers: 7.09 [1.51-14.33] vs. 28.52 [22.03-30.39] $\mu \mathrm{m}^{2} / \mu \mathrm{m}, P<0.001$ ) (Supplementary Fig. 3). In linear regression analysis, the association between diabetes and ACE2 + bronchial epithelium remained statistically significant after adjusting for age, sex, BMI, smoking status, inhaled and oral corticosteroid use, and comorbidities (Supplementary Fig. 4C, model 2).

Preoperative blood glucose levels were not significantly associated with higher levels of ACE2+ bronchial epithelium, but a trend toward a positive correlation was found (Supplementary Fig. 4C). In the subset of patients with diabetes and available $\mathrm{HbA}_{1 c}$ levels $(n=17)$, a significant age-adjusted linear association was found between $\mathrm{HbA}_{1 c}$ and ACE2+ bronchial epithelium (age-adjusted $\beta 7.99 \pm$ 3.08, $P=0.023)$.

\section{Pulmonary ACE2 mRNA Expression}

Pulmonary ACE2 mRNA expression was similar in subjects with or without diabetes (Fig. $3 A$ ). In linear regression analysis, no significant associations were found between diabetes, blood glucose levels, or $\mathrm{HbA}_{1 c}$ and ACE2 mRNA expression (Supplementary Fig. 4D).

\section{Pulmonary ACE2 Expression in Subjects With and Without RAAS Inhibitor Use}

To examine whether use of RAAS inhibitors confounded the association between diabetes and ACE2 expression, we studied the associations between different RAAS inhibitors and pulmonary ACE2 expression. Compared with control subjects without use of RAAS inhibitors $(n=64)$, subjects using ACE inhibitors $(n=14)$ exhibited significantly increased ACE2+ alveolar cell count and ACE2+ bronchial epithelium (Fig. 4), whereas subjects using ARBs $(n=15)$ exhibited significantly lower ACE2 mRNA expression (Fig. $3 B$ ). In a subset of patients with diabetes, no significant differences in ACE2 protein levels between users or 

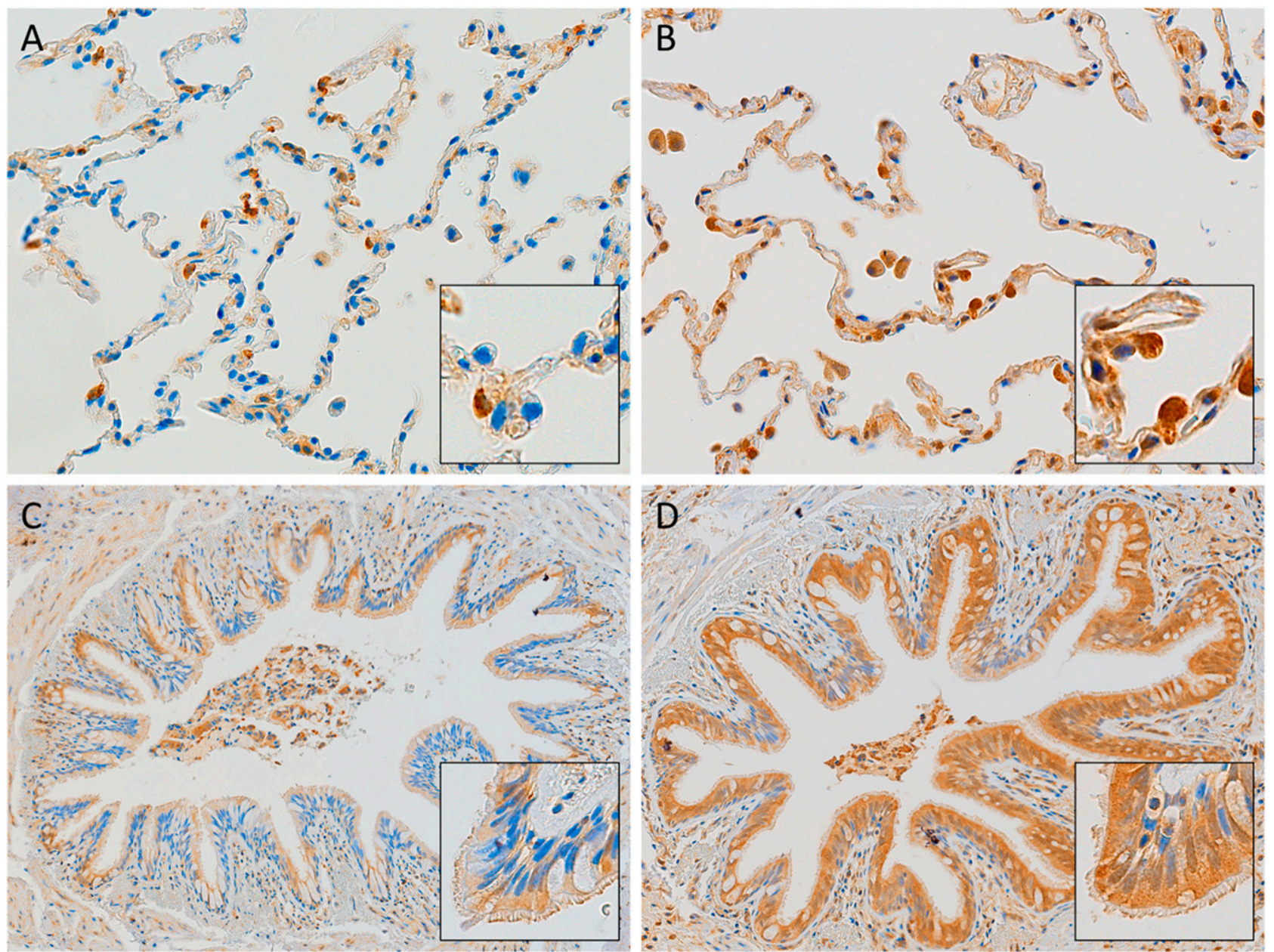

Figure 1-IHC of ACE2 protein expression in patients with and without diabetes. Representative images of ACE2 IHC staining showing positive signal in alveolar tissue of a subject without diabetes $(A)$, alveolar tissue of a subject with diabetes $(B)$, bronchial tissue of a subject without diabetes $(C)$, and bronchial tissue of a subject with diabetes $(D)$. Original magnification $\times 400$. Insets are a magnification of a selected area.

nonusers of different RAAS inhibitors were found (Fig. $4 A-C)$. Moreover, when adding ACE inhibitor and ARB use to the linear regression analysis, the association between diabetes and ACE2 + alveolar cell count (adjusted $\beta$ $306.98 \pm 142.71$ cells $\left./ \mathrm{mm}^{2}, P=0.035\right)$, percentage of ACE2+ alveolar tissue (0.96 $\pm 0.34 \%, P=0.005)$, and ACE2+ bronchial epithelium $\left(14.24 \pm 2.80 \mu \mathrm{m}^{2} / \mu \mathrm{m}, P<\right.$ 0.001 ) remained statistically significant. Finally, whereas the use of ACE inhibitors seemed to be associated with a nonsignificant trend to higher ACE2 protein and mRNA expression in adjusted linear regression analysis (Supplementary Fig. 4), ARB use was associated with significantly lower ACE2 mRNA expression, even after adjusting for potential confounders (Supplementary Fig. $4 D)$.

\section{DISCUSSION}

As SARS-CoV-2, the virus causing the COVID-19 pandemic, places health care systems around the world under great pressure, identification of patients at risk is crucial.
An increased risk of mortality and complications because of COVID-19 has been shown convincingly in patients with diabetes $(12,13,15,30)$, but pathophysiological mechanisms underlying these associations remain incompletely understood. It has been suggested that increased levels of ACE2, the host cell entry receptor of SARS-CoV-2, may explain increased infectivity or severity of COVID-19 in patients with diabetes (23). In this study, we demonstrate an increased expression of bronchial and alveolar ACE2 protein in lung tissue of patients with diabetes, independent of potential confounders such as smoking, BMI, comorbidities, and use of RAAS inhibitors. Moreover, we show a linear relationship between blood glucose levels and alveolar ACE2 protein expression and, in a subset of patients with diabetes, between $\mathrm{HbA}_{1 c}$ levels and ACE2+ bronchial epithelium.

First, we demonstrate increased ACE2 protein expression in both alveolar tissue and bronchial epithelium of patients with diabetes and a linear relationship between blood glucose levels and ACE2 expression in alveolar 

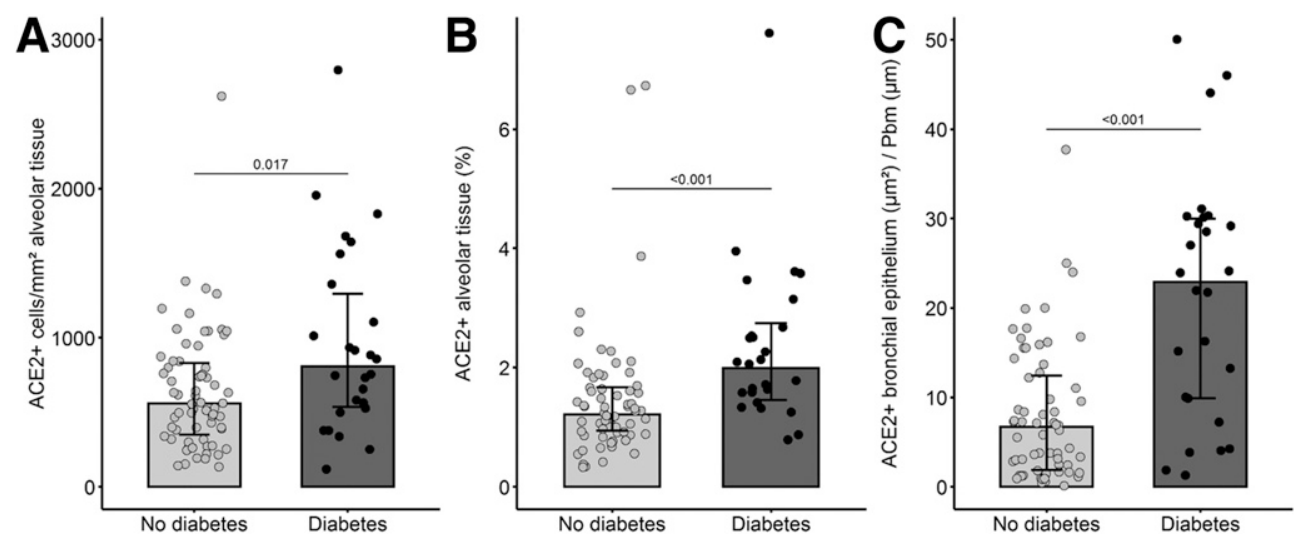

Figure 2-Pulmonary ACE2 protein expression in patients with and without diabetes. Bar plots depict median values of ACE2 + number in alveolar tissue $(A)$, ACE2 + percentage in alveolar tissue $(B)$, and amount ACE2 + signal measured in the bronchial epithelium $(C)$. Error bars represent 25th and 75th percentiles. $P$ values $<0.1$ are shown.

tissue. These findings are consistent with results from a phenomewide Mendelian randomization study describing a causal link between type 2 diabetes and increased ACE2 expression in the lung (31) and with findings from a genomewide association study in patients with COVID19 identifying a candidate gene, SLC6A20, which encodes the sodium-imino acid (proline) transporter 1 (SIT1), the expression of which depends on the presence of ACE2 (32). Also, these results correspond well with data from SARS-CoV-1 infection where both type 2 diabetes and hyperglycemia, which is a predictor for critical situations such as (inflammatory) stress, were determined as independent predictors of mortality and morbidity (33). Furthermore, increased ACE2 levels in lung, heart, kidney, and pancreas of nonobese diabetic mice have been reported $(24,34)$. Increased ACE2 protein levels in the lungs of diabetic mice even returned to normal when insulin was administered, suggesting a direct role of hyperglycemia on ACE2 protein levels in the lung (24). Also, high glucose levels in mice have previously been shown to activate the RAAS at the renin and angiotensinogen level (35-37).

We demonstrated that there are no differences in lungspecific ACE2 mRNA expression between subjects with and without diabetes, consistent with mRNA and protein discrepancies for ACE2 described in mice and humans $(34,38)$. mRNA levels were determined on total lung tissue (encompassing immune cells and many different structural cells, e.g., endothelial cells, fibroblasts, smooth muscle cells, in addition to epithelial cells), whereas protein levels were specifically determined in bronchial and alveolar epithelium, possibly explaining the different results.
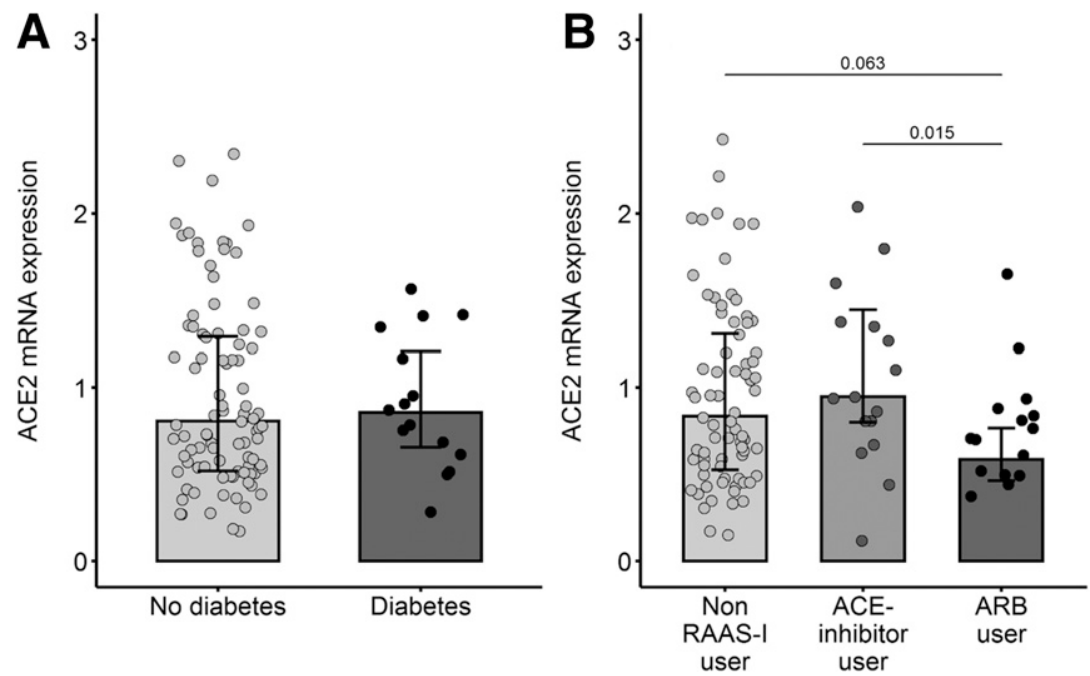

Figure 3-Pulmonary ACE2 mRNA expression according to diabetes and RAAS inhibitor use. Bar plots depict median values of ACE2 expression in patients with and without diabetes $(A)$ and in patients without RAAS inhibitor use, with ACE inhibitor use, and with ARB use (B). Error bars represent 25 th and 75 th percentiles. $P$ values $<0.1$ are shown. 


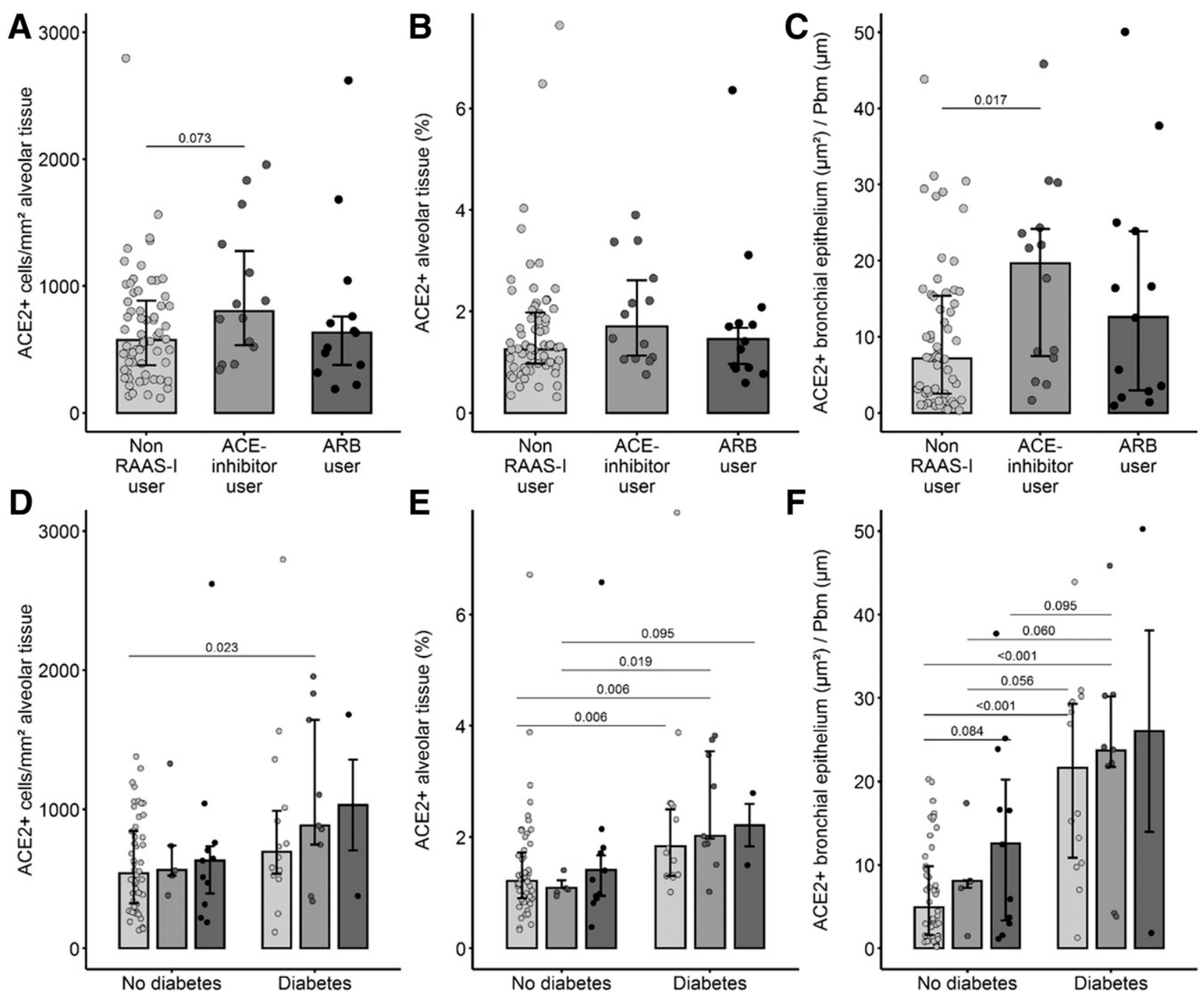

Figure 4-Pulmonary ACE2 protein expression according to RAAS inhibitor use and diabetes. Bar plots depict median values of ACE2 expression in patients without RAAS inhibitor use, with ACE inhibitor use, and with ARB use $(A-C)$ and stratified by diabetes $(D-F)$. Error bars represent 25th and 75th percentiles. $P$ values $<0.1$ are shown.

Alternatively, the discrepancy between mRNA and protein levels might be due to differences in RNA stability, receptor recycling, or protein shedding (39), as demonstrated for ACE (40).

Despite the clear link between diabetes and increased ACE2 levels, the pathophysiological mechanisms underlying this association remain incompletely understood. It has been suggested that a shift toward the protective ACE2/ angiotensin-(1-7)/MAS axis of RAAS could be part of a negative feedback system to compensate for the harmful effects of the ACE/angiotensin II (AGII)/angiotensin II type 1 receptor axis of RAAS in patients with diabetes and cardiovascular diseases. Supporting evidence can be found in studies of renal ACE2 expression. Young diabetic mice free from kidney disease expressed increased ACE2 levels in the renal cortex $(24,34,41,42)$. On the other hand, rats or people with diabetic kidney disease exhibited decreased glomerular and tubular ACE2 mRNA and protein expression (38,43-45), likely contributing to the development of glomerular injury (43).

Second, the increased alveolar and bronchial ACE2 protein levels in lung tissue of subjects with diabetes were independent of potential confounders such as age, smoking, BMI, COPD, cardiovascular comorbidities, and medication use. It has been suggested that ACE2 levels in patients with diabetes might be altered because of RAAS inhibitor use (23). However, by conducting multivariable linear regression analyses, we confirmed the significant and independent association between diabetes and pulmonary ACE2 protein expression. Moreover, we showed a linear association between glucose levels and ACE2 protein expression. In contrast, no statistically significant association was found between RAAS inhibitor use and ACE2 expression. ARB use tended to be associated with lower ACE2 mRNA expression, but this association lost statistical significance after multivariable adjustment 
$(P=0.08)$. Results from this study therefore suggest a role of diabetes and serum glucose-and to a lesser extent of RAAS inhibitors-on pulmonary ACE2 protein levels both in alveolar tissue and in bronchial epithelium. Poorly controlled glycemia has recently been suggested to cause more severe COVID-19, supporting this hypothesis (16). More specifically, both the viral spike $S$ protein and ACE2 are highly glycosylated at evolutionarily wellconserved sites, and alterations in glycation might thus modulate viral binding (16). In addition, SARS-CoV-1 has been shown to bind to ACE2 in the pancreas, resulting in damaged islets and reduced insulin release, suggesting a direct metabolic link between SARS infection and diabetes (46). Alternatively, new-onset diabetes has been reported in COVID-19, supporting the hypothesis of a potential diabetogenic effect of SARS-CoV-2 as seen in various (inflammatory) stress situations (18). None of the lung samples in this study originated from patients infected with SARS-CoV-2, ascertaining the robustness of our findings of increased ACE2 expression in lung tissue of patients with diabetes.

We argue that an increased infectivity of SARS-CoV-2 in patients with diabetes could be partially attributed to increased ACE2 expression in the upper and lower airways $(47,48)$ and that pulmonary ACE2 levels may play a role in the severity of COVID-19 in patients with diabetes. First, high levels of membrane-bound ACE2 facilitate binding of SARS-CoV-2, increasing the viral load. The increase in viral load may facilitate alveolar infection in subjects with initial tracheobronchitis. Second, after initial binding to ACE2, infection with SARS-CoV-2 downregulates cellular expression of ACE2, preventing ACE2 from exerting its beneficial roles (49). The removal of this AGII counterbalancing effect of ACE2 contributes to acute lung injury. This is especially true for patients with diabetes, who may rely on a negative feedback loop, where ACE2 is upregulated to overcome the harmful effects of AGII. In addition, widespread pulmonary vascular endothelialitis and thrombosis have been observed in autopsy specimens of patients who died as a result of COVID-19 (50), which might be mediated by expression of ACE2 in endothelial cells. Indeed, intracellular presence of SARS-CoV-2 in endothelial cells has been described and linked to severe endothelial injury and angiogenesis (50).

The main strength of our study is the large number of lung tissue samples from well-phenotyped subjects that have been included in both the mRNA expression and IHC staining analyses. By quantifying pulmonary ACE2 protein expression in human lung tissue of patients with and without diabetes, we provide a reference for the suggested hypothesis that increased pulmonary ACE2 expression in patients with diabetes may attribute to their increased risk for a more severe clinical course of COVID-19. However, because of the observational nature of this study, certain limitations should be kept in mind. First, by recruiting patients undergoing lobectomy, we cannot exclude selection bias. Second, although this study consisted of a relatively large and well-phenotyped cohort, samples sizes may have been insufficient for performing multivariable linear regression analyses, resulting in some nonsignificant results. Third, factors such as postoperative blood transfusions and increased erythrocytosis as a result of blood loss may influence postoperative $\mathrm{HbA}_{1 c}$ levels, and conclusions concerning these levels should therefore be confirmed in further research. Finally, levels of ACE2 protein in the alveolar tissue and bronchial epithelium as well as pulmonary ACE2 mRNA levels are influenced by multiple factors, including genetic polymorphisms, environmental factors, disease conditions, and therapy interactions among other yet-not-known variables.

In conclusion, we report increased ACE2 protein levels in both bronchial epithelium and alveolar tissue of patients with type 2 diabetes. Further research is needed to determine whether the observed upregulation has consequences on infectivity and severity of COVID-19. Moreover, the association between increased glucose levels and pulmonary expression of ACE2 in subjects with diabetes in our study implicates that optimal metabolic control of patients with diabetes remains an important goal, also during this pandemic.

Acknowledgments. The authors thank Greet Barbier, Indra De Borle, Katleen De Saedeleer, Anouck Goethals, and Ann Neesen from the Laboratory for Translational Research in Obstructive Pulmonary Diseases, Department of Respiratory Medicine, Ghent University Hospital, for excellent technical assistance. Funding. The research described in this article was supported by the Concerted Research Action of the Ghent University (Bijzonder Onderzoeksfonds grant 01G00819) and by the Fonds Wetenschappelijk Onderzoek in Flanders (FWO Vlaanderen grant G052518N and 3G037618 and EOS-contract G0G2318N).

Duality of Interest. G.F.J. reports grants from AstraZeneca, Chiesi, GlaxoSmithKline, and Teva and personal fees from Bayer, Eureca, and GlaxoSmithKline outside the submitted work; all fees were payed to the department. G.G.B. reports personal fees from AstraZeneca, Boehringer Ingelheim, Chiesi, GlaxoSmithKline, Novartis, Sanofi, and Teva outside the submitted work. No other potential conflicts of interest relevant to this article were reported.

Author Contributions. S.R.A.W., M.J., H.P.V.E., B.L., G.F.J., K.R.B., and G.G.B. contributed to the writing of the article or substantial involvement in its revision before submission. S.R.A.W., M.J., H.P.V.E., and K.R.B. contributed to the acquisition of the data or the analysis and interpretation of information. M.J., G.F.J., K.R.B., and G.G.B. were involved in the conception, hypotheses delineation, and design of the study. G.G.B. is the guarantor of this work and, as such, had full access to all the data in the study and takes responsibility for the integrity of the data and the accuracy of the data analysis.

\section{References}

1. Zhou $P$, Yang $X-L$, Wang $X-G$, et al. A pneumonia outbreak associated with a new coronavirus of probable bat origin. Nature 2020;579:270-273

2. CDC COVID-19 Response Team. Preliminary estimates of the prevalence of selected underlying health conditions among patients with coronavirus disease 2019 - United States, February 12-March 28, 2020. MMWR Morb Mortal Wkly Rep 2020;69:382-386

3. Li X, Xu S, Yu M, et al. Risk factors for severity and mortality in adult COVID19 inpatients in Wuhan. J Allergy Clin Immunol 2020;146:110-118

4. Richardson S, Hirsch JS, Narasimhan M, et al. Presenting characteristics, comorbidities, and outcomes among 5700 patients hospitalized with COVID-19 in the New York City Area [published correction appears in JAMA 2020;323:2098]. JAMA 2020;323:2052-2059 
5. Bhatraju PK, Ghassemieh BJ, Nichols M, et al. Covid-19 in critically ill patients in the Seattle region - case series. N Engl J Med 2020;382:2012-2022

6. EpiCentro. Characteristics of COVID-19 patients dying in Italy. Accessed 9 May 2020. Available from https://www.epicentro.iss.it/en/coronavirus/sars-cov -2-analysis-of-deaths

7. Guan W, Liang W, Zhao Y, et al. Comorbidity and its impact on 1590 patients with covid-19 in China: a nationwide analysis. Eur Respir J 2020;55:2000547

8. Grasselli G, Zangrillo A, Zanella A, et al.; COVID-19 Lombardy ICU Network. Baseline characteristics and outcomes of 1591 patients infected with SARS-CoV-2 admitted to ICUs of the Lombardy region, Italy. JAMA 2020;323:1574-1581

9. Wu C, Chen $X$, Cai $Y$, et al. Risk factors associated with acute respiratory distress syndrome and death in patients with coronavirus disease 2019 Pneumonia in Wuhan, China. JAMA Intern Med 2020;180:934-943

10. Liang $\mathrm{W}$, Liang $\mathrm{H}, \mathrm{Ou} \mathrm{L}$, et al. Development and validation of a clinical risk score to predict the occurrence of critical illness in hospitalized patients with COVID-19. JAMA Intern Med 2020;180:1081-1089

11. Zoppini G, Fedeli U, Schievano E, et al. Mortality from infectious diseases in diabetes. Nutr Metab Cardiovasc Dis 2018;28:444-450

12. Zhou F, Yu T, Du R, et al. Clinical course and risk factors for mortality of adult inpatients with COVID-19 in Wuhan, China: a retrospective cohort study. Lancet 2020;395:1054-1062

13. Remuzzi A, Remuzzi G. COVID-19 and Italy: what next? Lancet 2020;395: $1225-1228$

14. Onder G, Rezza G, Brusaferro S. Case-fatality rate and characteristics of patients dying in relation to COVID-19 in Italy. JAMA 2020;323:1775-1776

15. Fadini GP, Morieri ML, Longato E, Avogaro A. Prevalence and impact of diabetes among people infected with SARS-CoV-2. J Endocrinol Invest 2020;43: 867-869

16. Brufsky A. Hyperglycemia, hydroxychloroquine, and the COVID-19 pandemic. J Med Virol 2020;92:770-775

17. Bornstein SR, Dalan R, Hopkins D, Mingrone G, Boehm BO. Endocrine and metabolic link to coronavirus infection. Nat Rev Endocrinol 2020;16:297-298

18. Rubino F, Amiel SA, Zimmet $P$, et al. New-onset diabetes in Covid-19. N Engl J Med 2020;383:789-790

19. Saeedi P, Petersohn I, Salpea P, et al.; IDF Diabetes Atlas Committee. Global and regional diabetes prevalence estimates for 2019 and projections for 2030 and 2045: results from the International Diabetes Federation Diabetes Atlas, $9^{\text {th }}$ edition. Diabetes Res Clin Pract 2019;157:107843

20. Xu X, Chen P, Wang J, et al. Evolution of the novel coronavirus from the ongoing Wuhan outbreak and modeling of its spike protein for risk of human transmission. Sci China Life Sci 2020;63:457-460

21. Leung JM, Yang CX, Tam A, et al. ACE-2 expression in the small airway epithelia of smokers and COPD patients: implications for COVID-19. Eur Respir J 2020;55:2000688

22. Alqahtani JS, Oyelade T, Aldhahir AM, et al. Prevalence, severity and mortality associated with COPD and smoking in patients with COVID-19: a rapid systematic review and meta-analysis. PLoS One 2020;15:e0233147

23. Fang L, Karakiulakis G, Roth M. Are patients with hypertension and diabetes mellitus at increased risk for COVID-19 infection? Lancet Respir Med 2020;8:e21

24. Roca-Ho H, Riera M, Palau V, Pascual J, Soler MJ. Characterization of ACE and ACE2 expression within different organs of the NOD mouse. Int J Mol Sci 2017; 18:563

25. Harhay MO, Donaldson GC. Guidance on statistical reporting to help improve your chances of a favorable statistical review. Am J Respir Crit Care Med 2020; 201:1035-1038

26. Vandenbroucke JP, von Elm E, Altman DG, et al.; STROBE Initiative. Strengthening the Reporting of Observational Studies in Epidemiology (STROBE): explanation and elaboration. PLoS Med 2007;4:e297

27. Seys LJM, Verhamme FM, Schinwald $A$, et al. Role of $B$ cell-activating factor in chronic obstructive pulmonary disease. Am J Respir Crit Care Med 2015;192: 706-718
28. Vandesompele J, De Preter K, Pattyn F, et al. Accurate normalization of realtime quantitative RT-PCR data by geometric averaging of multiple internal control genes. Genome Biol 2002;3:research0034.1

29. Levey AS, Stevens LA, Schmid CH, et al.; CKD-EPI (Chronic Kidney Disease Epidemiology Collaboration). A new equation to estimate glomerular filtration rate. Ann Intern Med 2009;150:604-612

30. Muniyappa R, Gubbi S. COVID-19 pandemic, coronaviruses, and diabetes mellitus. Am J Physiol Endocrinol Metab 2020;318:E736-E741

31. Rao S, Lau A, So H-C. Exploring diseases/traits and blood proteins causally related to expression of ACE2, the putative receptor of SARS-CoV-2: a Mendelian randomization analysis highlights tentative relevance of diabetes-related traits. Diabetes Care 2020;43:1416-1426

32. Ellinghaus D, Degenhardt F, Bujanda L, et al.; Severe Covid-19 GWAS Group. Genomewide association study of severe Covid-19 with respiratory failure. N Engl J Med 2020;383:1522-1534

33. Yang JK, Feng Y, Yuan MY, et al. Plasma glucose levels and diabetes are independent predictors for mortality and morbidity in patients with SARS. Diabet Med 2006;23:623-628

34. Wysocki J, Ye M, Soler MJ, et al. ACE and ACE2 activity in diabetic mice. Diabetes 2006;55:2132-2139

35. Hsieh T-J, Zhang S-L, Filep JG, Tang S-S, Ingelfinger JR, Chan JSD. High glucose stimulates angiotensinogen gene expression via reactive oxygen species generation in rat kidney proximal tubular cells. Endocrinology 2002;143:29752985

36. Singh R, Leehey DJ. Effect of ACE inhibitors on angiotensin II in rat mesangial cells cultured in high glucose. Biochem Biophys Res Commun 2007;357:1040-1045 37. Zhang SL, Filep JG, Hohman TC, Tang SS, Ingelfinger JR, Chan JS. Molecular mechanisms of glucose action on angiotensinogen gene expression in rat proximal tubular cells. Kidney Int 1999;55:454-464

38. Mizuiri S, Hemmi H, Arita M, et al. Expression of ACE and ACE2 in individuals with diabetic kidney disease and healthy controls. Am J Kidney Dis 2008;51:613623

39. Gembardt F, Sterner-Kock A, Imboden H, et al. Organ-specific distribution of ACE2 mRNA and correlating peptidase activity in rodents. Peptides 2005;26: 1270-1277

40. Alfalah M, Parkin ET, Jacob R, et al. A point mutation in the juxtamembrane stalk of human angiotensin I-converting enzyme invokes the action of a distinct secretase. J Biol Chem 2001;276:21105-21109

41. Ye M, Wysocki J, Naaz P, Salabat MR, LaPointe MS, Batlle D. Increased ACE 2 and decreased ACE protein in renal tubules from diabetic mice: a renoprotective combination? Hypertension 2004;43:1120-1125

42. Riera M, Márquez E, Clotet $\mathrm{S}$, et al. Effect of insulin on ACE2 activity and kidney function in the non-obese diabetic mouse. PLoS One 2014;9:e84683 43. Wong DW, Oudit GY, Reich $\mathrm{H}$, et al. Loss of angiotensin-converting enzyme-2 (Ace2) accelerates diabetic kidney injury. Am J Pathol 2007;171:438-451

44. Tikellis $\mathrm{C}$, Johnston $\mathrm{Cl}$, Forbes $\mathrm{JM}$, et al. Characterization of renal angiotensinconverting enzyme 2 in diabetic nephropathy. Hypertension 2003;41:392-397 45. Reich HN, Oudit GY, Penninger JM, Scholey JW, Herzenberg AM. Decreased glomerular and tubular expression of ACE2 in patients with type 2 diabetes and kidney disease. Kidney Int 2008;74:1610-1616

46. Yang J-K, Lin S-S, Ji X-J, Guo L-M. Binding of SARS coronavirus to its receptor damages islets and causes acute diabetes. Acta Diabetol 2010;47:193-199 47. Peters MC, Sajuthi S, Deford P, et al. COVID-19-related genes in sputum cells in asthma. Relationship to demographic features and corticosteroids. Am J Respir Crit Care Med 2020;202:83-90

48. Bunyavanich S, Do A, Vicencio A. Nasal gene expression of angiotensinconverting enzyme 2 in children and adults. JAMA 2020;323:2427-2429 49. Kuba $\mathrm{K}$, Imai $\mathrm{Y}$, Rao $\mathrm{S}$, et al. A crucial role of angiotensin converting enzyme 2 (ACE2) in SARS coronavirus-induced lung injury. Nat Med 2005;11:875-879 50. Ackermann M, Verleden SE, Kuehnel M, et al. Pulmonary vascular endothelialitis, thrombosis, and angiogenesis in Covid-19. N Engl J Med 2020;383: 120-128 